\title{
Fifty-Year-Follow-up Results Compared with Shorter Follow-up of Breast Cancer Patients Undergoing Radical Mastectomy with or without Adjuvant Radiotherapy
}

\author{
Yoshiyuki Yoshida1,2, Hitoshi Obayasi ${ }^{3}$, Shunzo Maetani ${ }^{3 *}$ \\ ${ }^{1}$ Kyoto University Hospital, 53 Shogoin Kawahaara-cho, Kyoto, Japan \\ ${ }^{2}$ Tomita Hospital, 56 Koyama Shimouchi Kawahara-cho, Kyoto, Japan \\ ${ }^{3}$ Tenri Institute of Medical Research, 200 Mishima-cho, Tenri, Japan \\ Email: ^maetani@tenriyorozu.jp
}

How to cite this paper: Yoshida, Y., Obayasi, H. and Maetani, S. (2017) FiftyYear-Follow-up Results Compared with Shorter Follow-up of Breast Cancer Patients Undergoing Radical Mastectomy with or without Adjuvant Radiotherapy. Advances in Breast Cancer Research, 6, 81-91.

https://doi.org/10.4236/abcr.2017.63007

Received: April 26, 2017

Accepted: July 21, 2017

Published: July 24, 2017

Copyright $\odot 2017$ by authors and Scientific Research Publishing Inc. This work is licensed under the Creative Commons Attribution International License (CC BY 4.0).

http://creativecommons.org/licenses/by/4.0/

\begin{abstract}
Background: To evaluate the effect of follow-up length on the outcome of breast cancer patients, we compared the 50- and 25-year follow-up results in terms of cure rate, overall mortality and mortalities from breast cancer, second cancer, and benign diseases. Methods: 763 patients treated for breast cancer between February 1953 and September 1976, were followed up until December 2014. They were divided into two cohorts; earlier cohort exclusively underwent radical mastectomy plus adjuvant radiotherapy, while later cohort had radical mastectomy alone. Assuming that in all patients follow-up was terminated at 50 or 25 years after diagnosis, likelihood ratio test and stratified Log-rank tests were performed to evaluate the differences in cure rate and overall survival between the two cohorts. Results: During the 50 years, radical mastectomy alone compared with radical mastectomy plus adjuvant radiotherapy is associated with a significantly higher cure rate, and higher survivals regardless of whether the death was from breast cancer, second cancer, benign causes or any causes. However, if follow-up information is limited to 25 years, the advantage of radical mastectomy alone is partly offset and the survival difference between the two cohorts becomes less significant. Conclusion: Radiotherapy to breast cancer may adversely affect not only mortality from breast cancer, but mortalities unrelated to breast cancer. Since such deaths occur later, they may fail to be detected unless follow-up is long enough. Thus, deleterious effects of radiotherapy may be underestimated. Exceedingly long follow-up is required to accurately estimate the cure rate and the long-term effect of radiotherapy.
\end{abstract}




\section{Keywords}

Breast Cancer, Cure Rate, Long-Term Follow-up, Radical Mastectomy, Adjuvant Radiotherapy

\section{Introduction}

The goal of cancer therapy is to cure the disease rather than to prolong the time until death from the cancer; cure provides far more benefits than prolonged life with the remaining tumor. This is particularly true for younger patients who gain more benefits from cure than older patients. To promote cure, it is mandatory to determine which treatment is more curative in terms of having a higher cure rate. Unfortunately, as Cox himself acknowledges [1], the most commonly used methods of survival analysis such as the Cox proportional hazards regression [2] and the closely associated log-rank test [3] have limitations, failing to estimate the cure rate.

It is noteworthy that as early as 1949, Boag [4] estimated the cure rate using his survival model which has three parameters including the cure rate. By calculating these parameters, Boag estimated the probability of cure for several tumors including cancer of the breast. The advantage of his model is that its parameters provide the information for clinicians and patients eagerly seek, such as the patient's chance of being cured, and if not cured, the time to death from the cancer. Although the Boag model has been highly valued by clinicians and biostatisticians [5] [6] [7], it inherently has a serious difficulty; as compared with the standard methods of survival analysis, it requires a much longer follow-up time in order to distinguish between cure and delayed death from the cancer. This is particularly true for breast cancer patients who have much longer times to death than those with other malignancies.

Fortunately, we were able to overcome this difficulty. Since the registration of breast cancer started at the Kyoto University Hospital in 1953, the first author of the present paper (Y.Y.) assumed the responsibility to follow all patients who were surgically treated. If a patient was discharged, or hospitalized elsewhere, he made contact with the patient, her family members, her primary physician or the hospital staff. As a result, 41 patients were followed alive longer than 50 years. The purpose of the present paper is to gain a new insight into such extraordinarily long-term follow-up information, in particular, on the effects of adjuvant radiotherapy, which would not have been obtained without ordinary follow-up.

\section{Patients and Methods}

Of the 1023 Japanese women who were treated either at Kyoto University Hospital, or the Tomita Hospital from February 1953 to August 2002 for UICC [8] Stage I to IIIa breast cancer, 763 patients who were diagnosed earlier than September 1976 formed the basis for the present study. The reason why we excluded more recently diagnosed patients from this study was that their follow-up times 
were not long enough for cure rate estimation. Furthermore, if they had been included in the study, more recent anticancer regimens not available earlier, such as tegafur and tamoxifen might have been used and introduced biases in comparing two treatment cohorts.

When the breast cancer registration started in 1953, there was a policy to treat resectable cancer by Halsted's radical mastectomy [9] followed by adjuvant radiotherapy. Thus, only 9 patients had breast-conserving surgery, and they were excluded from the survival analysis; all of the remaining 754 patients underwent radical mastectomy.

In October 1961, adjuvant X-ray therapy was replaced by 60Co gamma-ray. It was initiated within three weeks after surgery. Treatment plans were individualized depending on the site and extension of the tumour. Usually, two areas were selected for irradiation among the following five areas: the chest wall, axilla, sternal, supraclavicular, and infraclavicular regions. Radiotherapy was delivered in five fractions per week in a dose of $150 \mathrm{rad}$ per day over six weeks. The maximum dose was 4500 rad.

Such radiotherapy was continued until May 1967, when the first author took over the chief of the Breast Surgery Section and totally abolished adjuvant radiotherapy while the radical mastectomy procedure was continued as before. This change in policy gave us the chance to compare two treatment cohorts, one with radical mastectomy alone (309 controls) versus the other with radical mastectomy plus radiotherapy (445 patients).

When patients died during the follow-up period, their deaths were classified into the following 3 types: 1) death from the original breast cancer; 2) death from second cancers including one from the contralateral breast cancer; and 3) death from benign causes. Those who were either alive at the last follow-up or lost to follow-up were censored. The Kaplan-Meier survival curves were plotted using each of the above three deaths as an event. Another survival curve (overall survival curve) was plotted for a group who died of any cause.

\section{Statistical Analysis}

In order to determine the cure rate, we estimated the three parameters of the Boag Model [4] which assumes that of a group of cancer patients a fraction $c$ are completely cured by treatment, while the remaining $1-\mathrm{c}$ are incurable and their failure times follow a log-normal distribution with mean $\mathrm{m}$ and standard deviation $s$ unless they die from other causes. The three parameters $(c, m, s)$ of the Boag model were estimated using the Gamel model [10] as shown below:

$$
\begin{gathered}
c=\frac{\exp \left(c_{0}+c_{1} x_{1}+c_{2} x_{2}+\cdots\right)}{1+\exp \left(c_{0}+c_{1} x_{1}+c_{2} x_{2}+\cdots\right),} \\
m=m_{0}+m_{1} y_{1}+m_{2} y_{2}+\cdots, \\
s=\exp \left(s_{0}+s_{1} z_{1}+s_{2} z_{2}+\cdots\right) .
\end{gathered}
$$

This model is the extension of the Boag model to three regressions (1), (2), (3), whose dependent variables are the cure rate (c), and the mean (m) and standard deviation(s) of log failure times, respectively; their independent va- 
riables are covariates of the regressions $\left(x_{i}, y_{j}, z_{k}\right)$. Using the maximum likelihood method, the regression coefficients $\left(c_{i}, m_{j}, s_{k} ; i, j, k=0,1,2, \cdots\right)$ were estimated along with their standard errors. The Boag parameters were then derived from the regressions. Graphically, if the disease-specific survival curve levels off in parallel with the time axis, its distance from the time axis is considered the cure rate.

The hypothesis that there is no difference in cure rate between radical mastectomy alone and radical mastectomy plus adjuvant radiotherapy was tested by the likelihood ratio test $\chi 21$ (Klein) [11]. Another hypothesis that there is no survival difference between the two cohorts was evaluated by the log-rank test [12] stratified by UICC N-categories [9].

Patients were divided according to covariate values into subgroups. For each subgroup, the cure rate (c) was compared with the 5-year overall survival rate using the paired $t$-test.

In order to evaluate the effect of short follow-up length (e.g., 5 years) on the results of survival analyses, imaginary data were created by decreasing the observed follow-up length to a shorter length (e.g., from "died at 7.2 years" to "censored at 5 years"), and survival analyses were carried out.

\section{Results}

Of the 763 patients, 41 survived 50 years, 83 were still alive as of December 31, 2014. The individual follow-up times ranged from 8 days to 61.9 years, with a median of 20.5 years. A total of 204 died of the original breast cancer, 143 from second malignancies, and 326 from benign diseases. Seven patients were lost to follow-up from 2.4 to 8.5 years.

In Table 1, the cure rates for Stage 1 to Stage IIIa have been estimated as $\mathrm{c}$ of the Boag model using the limited follow-up information available at 5, 10, 20, and 40 years after diagnosis. Figure 1 shows that irrespective of the stage, when disease-specific survival curves are predicted using information available at 5

Table 1. Prediction of cure rate at different follow-up limit.

\begin{tabular}{|c|c|c|c|c|c|}
\hline & & \multicolumn{4}{|c|}{ Follow-Up Limit } \\
\hline & & $5 y$ & $10 \mathrm{y}$ & $20 y$ & $40 y$ \\
\hline & & \multicolumn{4}{|c|}{ Cure Rate $(95 \% \mathrm{CI})$} \\
\hline \multirow{4}{*}{$\begin{array}{l}\text { Stage } \\
\text { (Size) }\end{array}$} & $\begin{array}{c}\mathrm{I} \\
(217)\end{array}$ & $\begin{array}{c}0.921 \\
(0.864 \text { to } 0.955)\end{array}$ & $\begin{array}{c}0.859 \\
(0.791 \text { to } 0.908)\end{array}$ & $\begin{array}{c}0.849 \\
\text { (0.791 to } 0.893)\end{array}$ & $\begin{array}{c}0.821 \\
(0.757 \text { to } 0.870)\end{array}$ \\
\hline & $\begin{array}{c}\text { IIA } \\
(219)\end{array}$ & $\begin{array}{c}0.853 \\
\text { (0.729 to } 0.926)\end{array}$ & $\begin{array}{c}0.724 \\
(0.521 \text { to } 0.864)\end{array}$ & $\begin{array}{c}0.772 \\
\text { (0.705 to } 0.828)\end{array}$ & $\begin{array}{c}0.739 \\
(0.667 \text { to } 0.800)\end{array}$ \\
\hline & $\begin{array}{l}\text { IIB } \\
(227)\end{array}$ & $\begin{array}{c}0.781 \\
\text { (0.622 to } 0.885)\end{array}$ & $\begin{array}{c}0.741 \\
\text { (0.662 to } 0.801)\end{array}$ & $\begin{array}{c}0.663 \\
\text { (0.582 to } 0.736)\end{array}$ & $\begin{array}{c}0.647 \\
(0.571 \text { to } 0.716)\end{array}$ \\
\hline & $\begin{array}{l}\text { IIIA } \\
(100)\end{array}$ & $\begin{array}{c}0.533 \\
(0.369 \text { to } 0.690)\end{array}$ & $\begin{array}{c}0.450 \\
(0.339 \text { to } 0.566)\end{array}$ & $\begin{array}{c}0 . .396 \\
(0.295 \text { to } 0.507)\end{array}$ & $\begin{array}{c}0.401 \\
(0.302 \text { to } 0.510)\end{array}$ \\
\hline
\end{tabular}

For prediction of cure rate using full follow-up data, refer to Table 2. 

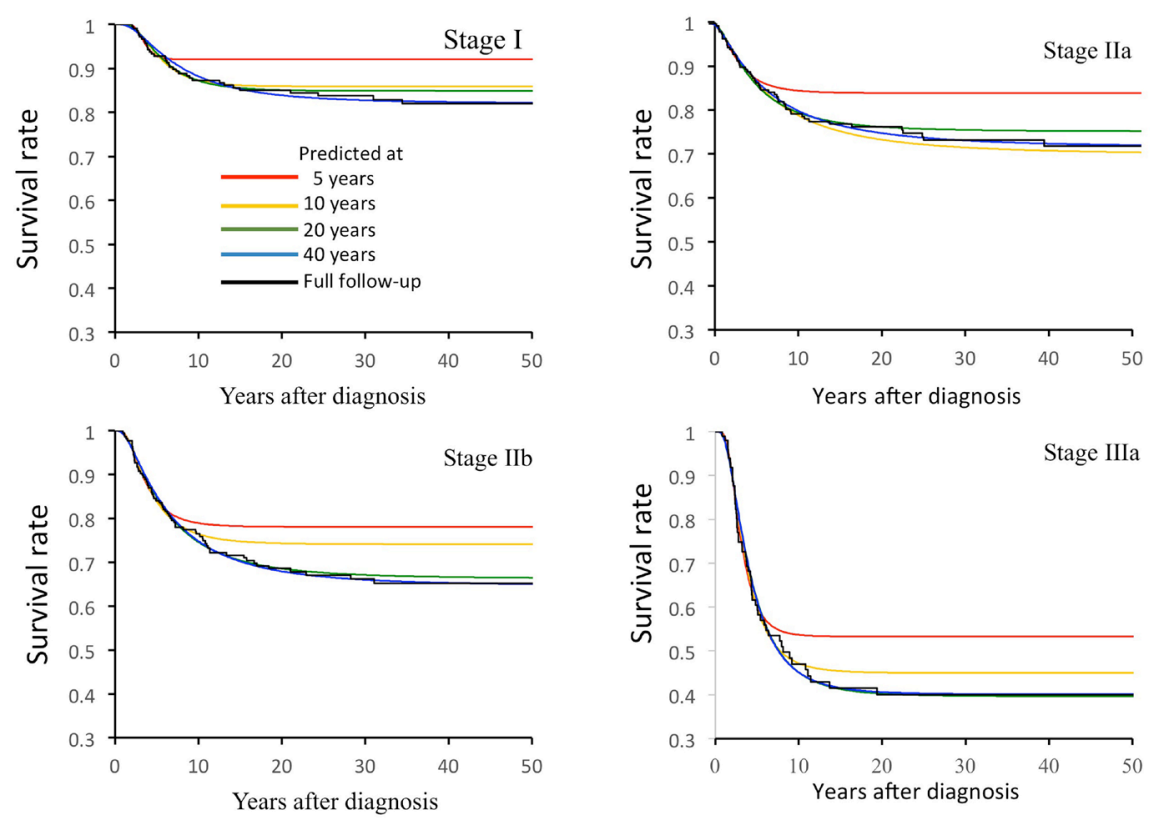

Figure 1. Survival curves predicted using limited follow-up information available at 5 to 40 years, respectively.

years, these parametric curves (red) diverge from the corresponding KaplanMeier curves (black), which are obtained by the full follow-up data. The predicted disease-specific survival curves failed to converge to the Kaplan-Meier curve (black) until after 40 years of follow-up.

In Table 2, the total patient population has been divided into two to five subgroups by various covariate values, thus generating a total of 31 subgroups. For each subgroup, the curability of breast cancer was assessed by the cure rate ranging from $3 \%$ to $88 \%$; the minimum cure rate is seen in the subgroup with metastasis (+), suggesting that patients with metastasis have very little chance of cure. The other subgroups whose cure rates $\leq 0.2$ are those with N2 disease and locoregional recurrence $(+)$. On the other hand, the maximum cure rate of $88 \%$ is encountered in the subgroup whose body weight $<40 \mathrm{~kg}$. Other subgroups whose cure rates $\geq 80 \%$ are those with N0 disease, metastasis (-), and Stage I.

When the cure rate is compared with the 5-year survival rate for each subgroup, there is a highly significant difference between them; the five year-survival is on average $10.5 \%$ higher than the cure rate (paired t-test $=6.71$ on $38 \mathrm{df}$, $P<0.0001)$.

Of note, the subgroup undergoing radical mastectomy plus adjuvant radiotherapy has a lower cure rate (67\%) than the subgroup undergoing radical mastectomy alone (75\%); the difference is significant based on the likelihood ratio test $\left(\chi_{1}^{2}=60.14, P<0.0001\right)$.

Figure 2 graphically shows impact of adjuvant radiotherapy (red) compared with radical mastectomy alone (blue) on Kaplan-Meier survival curves. This figure also shows how the survival curves differ depending on the type of events, which include (a): death from breast cancer, (b): death from second cancer, (c): death from benign diseases, and (d): death from any causes. Of the four pairs of 
Table 2. Long-term outcomes of breast cancer subgroups.

\begin{tabular}{|c|c|c|c|c|c|c|}
\hline Subgroups & $\begin{array}{l}\text { No. of } \\
\text { cases }\end{array}$ & $\begin{array}{l}\text { Deaths } \\
\text { from } \\
\text { breast } \\
\text { cancer }\end{array}$ & $\begin{array}{l}\text { Deaths } \\
\text { from } \\
\text { second } \\
\text { cancer }\end{array}$ & $\begin{array}{l}\text { Deaths } \\
\text { from } \\
\text { benign } \\
\text { causes }\end{array}$ & $\begin{array}{l}\text { Probability of } \\
\text { cure }(95 \% \text { CI })\end{array}$ & $\begin{array}{c}\text { 5-year } \\
\text { survival } \\
(95 \% \mathrm{CI})\end{array}$ \\
\hline \multicolumn{7}{|l|}{ Age (y) } \\
\hline$<45$ & 311 & 86 & 53 & 98 & $0.70(0.65-0.75)$ & $0.82(0.77-0.86)$ \\
\hline $45-54$ & 232 & 60 & 47 & 111 & $0.72(0.66-0.78)$ & $0.82(0.77-0.87)$ \\
\hline $55-64$ & 161 & 48 & 35 & 77 & $0.66(0.58-0.74)$ & $0.76(0.69-0.82)$ \\
\hline$\geq 65$ & 59 & 10 & 8 & 40 & $0.60(0.00-1.00)$ & $0.64(0.52-0.77)$ \\
\hline \multicolumn{7}{|l|}{ Stage } \\
\hline I & 217 & 34 & 46 & 95 & $0.82(0.77-0.88)$ & $0.88(0.84-0.93)$ \\
\hline IIa & 219 & 50 & 45 & 96 & $0.74(0.67-0.81)$ & $0.86(0.81-0.93)$ \\
\hline IIb & 227 & 67 & 39 & 101 & $0.65(0.58-0.72)$ & $0.75(0.69-0.80)$ \\
\hline IIIa & 100 & 53 & 13 & 34 & $0.40(0.30-0.51)$ & $0.54(0.44-0.64)$ \\
\hline \multicolumn{7}{|l|}{$\mathrm{T}$ disease } \\
\hline $\mathrm{T} 1$ & 290 & 59 & 59 & 122 & $0.77(0.72-0.82)$ & $0.87(0.83-0.90)$ \\
\hline $\mathrm{T} 2$ & 367 & 101 & 72 & 158 & $0.74(0.67-0.81)$ & $0.78(0.74-0.83)$ \\
\hline $\mathrm{T} 3$ & 106 & 44 & 12 & 46 & $0.54(0.43-0.64$ & $0.61(0.52-0.71)$ \\
\hline \multicolumn{7}{|l|}{$\mathrm{N}$ disease } \\
\hline No & 397 & 71 & 81 & 178 & $0.80(075-0.84)$ & $0.86(0.83-0.89)$ \\
\hline N1 & 323 & 104 & 57 & 139 & $0.63(057-0.69)$ & $0.75(0.71-0.80)$ \\
\hline $\mathrm{N} 2$ & 43 & 29 & 5 & 9 & $0.10(0.00-0.24)$ & $0.42(0.27-0.57)$ \\
\hline \multicolumn{7}{|l|}{ Radiotherapy } \\
\hline$(-)$ & 309 & 68 & 48 & 128 & $0.75(0.69-0.80)$ & $0.83(0.79-0.88)$ \\
\hline$(+)$ & 445 & 132 & 94 & 194 & $0.67(0.62-0.72)$ & $0.77(0.73-0.81)$ \\
\hline \multicolumn{7}{|c|}{ Body weight (kg) } \\
\hline$<40$ & 47 & 5 & 13 & 25 & $0.88(0.79-0.98)$ & $0.83(0.72-0.94)$ \\
\hline $40-59$ & 617 & 161 & 119 & 260 & $0.70(0.66-0.74)$ & $0.81(0.72-0.94)$ \\
\hline $60-69$ & 84 & 34 & 9 & 35 & $0.55(0.43-0.66)$ & $0.67(0.43-0.90)$ \\
\hline$\geq 70$ & 15 & 4 & 2 & 6 & $0.69(0.44-0.94)$ & $0.67(0.57-0.78)$ \\
\hline \multicolumn{7}{|l|}{ Height $(\mathrm{cm})$} \\
\hline$<150$ & 163 & 40 & 26 & 84 & $0.71(0.63-0.79)$ & $0.80(0.74-0.86)$ \\
\hline $150-159$ & 505 & 139 & 97 & 209 & $0.69(0.64-0.73)$ & $0.79(0.75-0.82)$ \\
\hline$\geq 160$ & 95 & 25 & 20 & 33 & $0.70(0.60-0.80)$ & $0.80(0.72-0.88)$ \\
\hline \multicolumn{7}{|c|}{ Body mass index } \\
\hline$<18$ & 55 & 10 & 17 & 23 & $0.77(0.64-0.91)$ & $0.78(0.67-0.89)$ \\
\hline $18-24$ & 586 & 147 & 114 & 251 & $0.72(0.68-0.76)$ & $0.81(0.78-0.84)$ \\
\hline $25-29$ & 111 & 42 & 10 & 48 & $0.58(0.47-0.67)$ & $0.73(0.65-0.81)$ \\
\hline$\geq 30$ & 11 & 5 & 2 & 4 & $0.54(0.25-0.84)$ & $0.54(0.25-0.84)$ \\
\hline \multicolumn{7}{|l|}{ Metastasis } \\
\hline$(-)$ & 576 & 31 & 137 & 319 & $0.83(0.80-0.86)$ & $0.85(0.82-0.88)$ \\
\hline$(+)$ & 178 & 169 & 5 & 3 & $0.03(0.00-0.09)$ & $0.52(0.43-0.60)$ \\
\hline \multicolumn{7}{|l|}{ Locoreg rec } \\
\hline$(-)$ & 715 & 169 & 140 & 318 & $0.72(0.68-0.76)$ & $0.81(0.78-0.84)$ \\
\hline$(+)$ & 39 & 31 & 2 & 4 & $0.14(0.02-0.25)$ & $0.51(0.42-0.60)$ \\
\hline
\end{tabular}

Stage, T-factor, N-factor: UICC TNM Classification 4th Edition. Radiotherapy: See the text. 


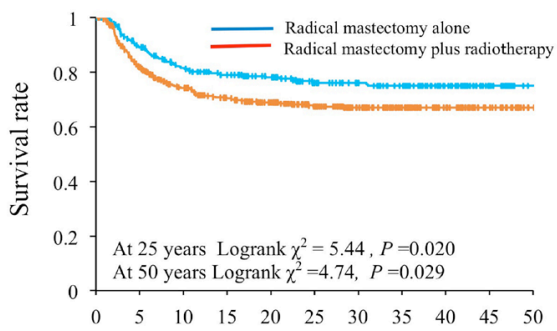

(a)

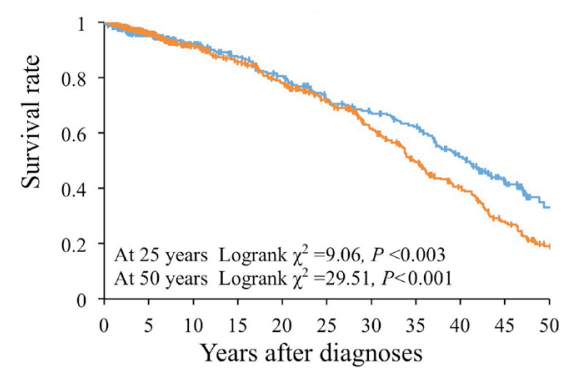

(c)

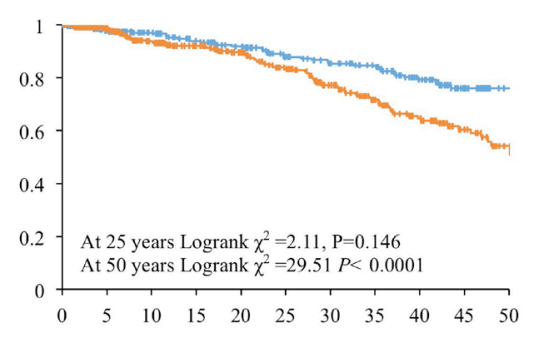

(b)

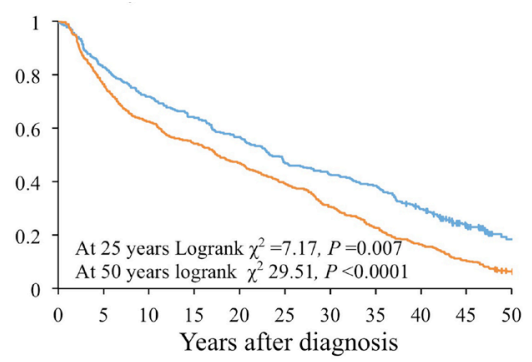

(d)

Figure 2. The effects of radical mastectomy alone compared with radical mastectomy plus adjuvant radiotherapy on Kaplan-Meier survival curves using four different deaths (a): death from breast cancer; (b): death from second cancer; (c): death from benign causes; (d): death from any cause. The log-rank tests are done assuming that, for every patient, follow-up is terminated at 25 and 50 years after diagnosis. If follow-up is assumed to be terminated at 25 years, a patient who actually died at 26 years is treated as censored at 25 years, whereas patients dying at 20 years are unchanged.

survival curves, the one whose death is from breast cancer (a) differs from the other three pairs in that the curves level off with time before dropping to zero, suggesting that the risk of death from breast cancer decreases with time. In contrast, the other three pairs of curves ((b), (c), (d)), in particular, those subjected to adjuvant radiotherapy continue to decline with time.

Figure 2 also shows the results of stratified log-rank tests assuming that the follow-up is terminated at 25 or 50 years after diagnosis. Thus, the results of the two tests using 25- and 50- year follow-up data are compared. They reveal that when patients are followed-up for 50 years, the effect of radical mastectomy alone compared with adjuvant radiotherapy always shows highly significant differences ((a): $P=0.029$, (b): $P<0.0001$, (c): $P<0.0001$, (d): $P<0.0001)$. However, when the follow-up time is shortened to 25 years, the difference in survival between the two cohorts became less significant ((a): $P=0.02$, (b): $P=0.146$, (c): $P=0.003,(\mathrm{~d}): P=0.007)$ except for A.

Another significant association with adjuvant radiotherapy was found between the latter and the risk of distant metastasis (Table 3, $P=0.05$ ). On the other hand, no significant association was found between the latter and the risk of locoregional recurrences $\left(\chi_{1}^{2}=0.245(P=0.621)\right.$ (Table 4).

\section{Discussion}

For many years, the overall survival rate at a given point in time, particularly, at 
Table 3. Association of adjuvant radiotherapy with metastasis.

\begin{tabular}{|c|c|c|c|}
\hline & \multicolumn{2}{|c|}{ Metastasis } & \multirow{2}{*}{ Total } \\
\hline & $(+)$ & $(-)$ & \\
\hline Radiotherapy (+) & 94 & 351 & 445 \\
\hline$(-)$ & 45 & 264 & 309 \\
\hline Total & 139 & 615 & 754 \\
\hline
\end{tabular}

$\chi_{1}^{2}=5.220(P=0.022)$.

Table 4. Association of adjuvant radiotherapy with locoregional recurrence.

\begin{tabular}{|c|c|c|c|}
\hline & \multicolumn{2}{|c|}{ Recurrence } & \multirow{2}{*}{ Total } \\
\hline & $(+)$ & $(-)$ & \\
\hline Radiotherapy (+) & 44 & 401 & 445 \\
\hline$(-)$ & 34 & 275 & 309 \\
\hline Total & 78 & 676 & 754 \\
\hline
\end{tabular}

$\chi_{1}^{2}=0.245(P=0.621)$.

five years, has been commonly used as an easy measure of cancer curability and treatment efficacy. However, our long-term follow-up study of breast cancer patients reveals that for this purpose, the overall 5 -year survival rate is heavily biased, being about $10 \%$ higher than the probability of cure. Although the use of other statistics such as the hazard ratio [1] and log-rank statistic [3] is advocated by biostatisticians, they do not appear to be easily comprehensible for the patients, who are now the major decision-makers in this era of patient-centered medicine.

It is noteworthy that in our extremely long-term follow-up study the cohort with radical mastectomy plus adjuvant radiotherapy compared with radical mastectomy alone is at a higher risk of not only death from breast cancer but also other types of deaths including death from second cancer, death from benign diseases, and death from any cause. In this respect, atomic bomb survivors in Hiroshima and our breast cancer patients receiving adjuvant radiotherapy exhibit similar features. According to Sakata et al. [13] their 60-year follow-up studies of atomic bomb survivors indicate that radiation exposure increases the risk of cancer at almost all sites, this increase remains throughout the lifetime of the survivors, and that radiation increases the incidence of and/or mortality due to diseases other than cancer.

On the other hand, our results are at variance with the results of a number of randomized trials and meta-analyses comparing surgery plus adjuvant radiotherapy to surgery alone; they show that, at least in some subsets of breast cancer patients, adjuvant radiotherapy results in better survival than surgery alone1 [4]-[23]. One of the possible explanations for such controversy may be excessive blood transfusion, which together with radiotherapy may have caused immunosuppression, predisposing patients to cancer recurrence, infectious diseases and 
other conditions [24] [25] [26] [27] [28]. Unfortunately, the amount of blood transfusion given to each patient was not obtainable, nor was the statistical interaction of transfusion with radiotherapy. Very likely, however, blood transfusion was given based on the Christpher's Textbook of Surgery [29] the most favorite book read by surgeons and medical students then, the author recommended blood transfusion in major surgeries as follows: daily infusions of 500 to $1000 \mathrm{cc}$ of whole blood should continue until the hemoglobin and hematocrit values reach and remain in the normal range.

Another important explanation for this controversy may be that the follow-up time of breast cancer patients which has been generally considered appropriate is insufficient to detect late deaths from second cancers and benign conditions. For example, it may take several decades for a patient with transfusion-related viral hepatitis to die from liver cancer or hepatic failure. Hence, even fifty-year follow-up might be insufficient to accurately evaluate the survival benefit of breast cancer patients [30].

\section{Conclusion}

In conclusion, radiotherapy to breast cancer may have adverse effects not only on the breast cancer per se, but on second cancer and benign diseases. Since these effects tend to occur later, insufficient follow-up may fail to detect late deaths and underestimate the deleterious effects of radiotherapy. Sufficiently long-term follow-up is essential for accurate assessment of the cure rate and true effect of radiotherapy.

\section{References}

[1] Cox, D.R. (2010) Summary Comments on Evolution of Cancer Survival Analysis. Surgical Oncology, 19, 49-61. https://doi.org/10.1016/j.suronc.2010.03.002

[2] Cox, D.R. (1972) Regression Models and Life-Table. Journal of the Royal Statistical Society Series B, 34,187-220.

[3] Peto, R. and Peto, J. (1972) Asymptotically Efficient Rank Invariant Test Procedures. Journal of the Royal Statistical Society Series A, 135, 185-206.

https://doi.org/10.2307/2344317

[4] Boag, J.W. (1949) Maximum Likelihood Estimates of the Proportion of Patients Cured by Cancer Therapy. Journal of the Royal Statistical Society, 118, 15-53.

[5] Rutqvist, L.E. and Wallgren, A. (1985) Long-Term Survival of 458 Young Breast Cancer Patients. Cancer, 55, 658-665.

https://doi.org/10.1002/1097-0142(19850201)55:3<658::AID-CNCR2820550331>3.0 .CO;2-P

[6] Gamel, J.W., Vogel, R.L. (1997) Comparison of Parametric and Non-Parametric Methods Using Simulated Clinical Data. Statistics in Medicine, 16, 1629-1643. https://doi.org/10.1002/(SICI)1097-0258(19970730)16:14<1629::AID-SIM594>3.0.C $\mathrm{O} ; 2-\mathrm{C}$

[7] Sposto, R. (2002) Cure Model Analysis in Cancer: An Application to Data from the Children's Cancer Group. Statistics in Medicine, 21, 293-312. https://doi.org/10.1002/sim.987

[8] UICC (2010) Breast Tumours. In: Sobin, L.H., Gospodarowicz, M.K. and Witte- 
kind, Ch., Eds., TNM Classification of Malignant Tumours, 7th Edition, Springer-Verlag, New York, 181-193.

[9] Halsted, W.S. (1907) The Results of Radical Operations for the Cure of Carcinoma of the Breast. Annals of Surgery, 46, 1-19. https://doi.org/10.1097/00000658-190707000-00001

[10] Gamel, J.W. and McLean, I.W. (1994) A Stable, Multivariate Extension of the Log-Normal Survival Model. Computer and Biostatistical Research, 27, 148-155. https://doi.org/10.1006/cbmr.1994.1014

[11] Klein, J.P. and Moeschberger, M.L. (1997) Large-Sample Test Based on Likelihood Ratio Theory. In: Survival Analysis, Spring Science + Business Media, Inc., New York, 459-463. https://doi.org/10.1007/978-1-4757-2728-9

[12] Kalbfleisch, J.D. and Prentice, R.L. (1980) Comparison of Survival Curves. In: The Statistical Analysis of Failure Time Data, John Wiley \& Sons, Inc., New York, 16-19.

[13] Sakata, R., Grant, E.I. and Ozawa, K. (2012) Long-Term Follow-Up of Atomic Bomb Survivors. Maturitas, 72, 99-103. https://doi.org/10.1016/j.maturitas.2012.02.009

[14] Klipworth, L. (1965) Survival of Cases of Surgically Treated Mammary Carcinoma with and without Radiation Therapy. The Lancet, 286, 231-232. https://doi.org/10.1016/S0140-6736(65)90714-2

[15] Host, H., Brennhovd, I.O. and Loeb, M. (1986) Postoperative Radiotherapy in Breast Cancer: Long-Term Results from the Oslo Study. International Journal of Radiation Oncology ${ }^{\star}$ Biology ${ }^{*}$ Physics, 12, 727-732. https://doi.org/10.1016/0360-3016(86)90029-5

[16] EBCTCG (2002) Radiotherapy for Early Breast Cancer. Cochrane Database of Systemic Reviews, No. 2, Article No. CD003647. https://doi.org/10.1002/14651858.CD003647

[17] Rutqvist, L.E., Rose, C. and Cavellin-Stahl, E. (2003) A Systematic Overview of Radiation Therapy Effects in Breast Cancer. Acta Oncologica, 42, 532-545. https://doi.org/10.1080/02841860310014444

[18] EBCTCG (2005) Effect of Radiotherapy and of Difference in the Extent of Surgery for Early Breast Cancer on Local Recurrences and 15-Year Survival: An Overview of the Randomized Trials. The Lancet, 366, 2087-2106. https://doi.org/10.1016/S0140-6736(05)67887-7

[19] EBCTCG (2011) Effect of Radiotherapy after Breast-Conserving Surgery on 10-Year Recurrence and 15-Year Breast Cancer Death: Meta-Analysis of Individual Patient Data for 10801 Women in 17 Randomised Trials. The Lancet, 378, 1707-1716. https://doi.org/10.1016/S0140-6736(11)61629-2

[20] EBCTCG (2014) Effect of Radiotherapy after Mastectomy and Axillary Surgery on 10-Year Recurrence and 20 Year Breast Cancer Mortality: Meta-Analysis of Individual Patient Data for 8135 Women in Randomized Trials. The Lancet, 383, 2127 2135. https://doi.org/10.1016/S0140-6736(14)60488-8

[21] Hennequin, C. and Fourquet, A. (2014) Controversy about Internal Mammary Chain Irradiation in Breast Cancer. Cancer Radiotherapie, 18, 3515.

[22] Poortmans, P.M., Collette, S., Kirkovw, C., et al. (2015) Internal Mammary and Medical Supraclavicular Irradiation in Breast Cancer. The New England Journal of Medicine, 373, 317-327. https://doi.org/10.1056/NEJMoa1415369

[23] Drooger, J.C., Hooning, M.J., Seynaeve, C.M., et al. (2015) Diagnostic and Therapeutic Ionizing Radiation and the Risk of a First and Second Primary Breast Cancer, with Special Attention for BRCA1 and BRCA2 Mutation Carriers: A Critical Review 
of the Literature. Cancer Treatment Review, 41, 187-196. https://doi.org/10.1016/j.ctrv.2014.12.002

[24] Weiden, P.L. (1990) Do Perioperative Blood Transfusions Increase the Risk of Cancer Recurrence? European Journal of Cancer, 26, 987-989.

[25] Bhagwat, G.P. (1990) Blood Transfusion and Cancer Recurrence: A Brief Review. Bahrain, 12, 79-83.

[26] Dellinger, E.P. and Anaya, D.A. (2004) Infectious and Immunologic Consequences of Blood Transfusion. Critical Care, 8, S18-S23. https://doi.org/10.1186/cc2847

[27] Vamvakas, E.C. and Blajchman, M.A. (2007) Transfusion-Related Immunomodulation (TRIM): An Update. Blood Reviews, 21, 327-348. https://doi.org/10.1016/j.blre.2007.07.003

[28] Cata, J.P., Wang, H., Gottumukkala, V., Rheuban, J. and Sessler, D.I. (2013) Inflammatory Response, Immunosuppression, and Cancer Recurrence after Perioperative Blood Transfusion. British Journal of Anaesthesia, 110, 690-701. https://doi.org/10.1093/bja/aet068

[29] Valco, R.L. (1956) Principles of Pre- and Postoperative Care. In: Davis, L., Ed., Christopher's Textbook of Surgery, 6th Edition, W. B. Saunders, Philadelphia, 109-142.

[30] Maetani, S. and Gamel, J.W. (2013) Parametric Cure Model versus Proportional Hazards Model in Survival Analysis of Breast Cancer and Other Malignancies. Advances in Breast Cancer Research, 2, 119-125.

https://doi.org/10.4236/abcr.2013.24020

\section{Submit or recommend next manuscript to SCIRP and we will provide best} service for you:

Accepting pre-submission inquiries through Email, Facebook, LinkedIn, Twitter, etc. A wide selection of journals (inclusive of 9 subjects, more than 200 journals)

Providing 24-hour high-quality service

User-friendly online submission system

Fair and swift peer-review system

Efficient typesetting and proofreading procedure

Display of the result of downloads and visits, as well as the number of cited articles

Maximum dissemination of your research work

Submit your manuscript at: http://papersubmission.scirp.org/

Or contact abcr@scirp.org 